\title{
New Space-Vector Hysteresis Current Control with Neutral Point Voltage Balancing Applied on Three-Level VSI for Wind Power Conversion
}

\author{
T. Ghennam ${ }^{1}$, E.M.Berkouk ${ }^{2}$, B.François ${ }^{3}$, K.Aliouane ${ }^{4}$ K.Merouani $^{5}$ \\ ${ }^{1,485}$ Unité d'enseignement et de recherche UER-ELT, EMP (EX: ENITA), BP 17 Bordj-El-Bahri, Algiers, Algeria \\ Fax (213) 218632 04, Email : t_ghennam@yahoo.fr, kam-ali@lycos.com, marouani_khoudir@yahoo.fr \\ ${ }^{2}$ Laboratoire de Commande des Processus (LCP), ENP, Algiers, Algeria \\ Fax:(213)21.52.29.73 Email : emberkouk@yahoo.fr \\ ${ }^{3}$ Laboratoire d'Electrotechnique et d'Electronique de Puissance de Lille (L2EP) E.C. Lille, France. \\ Fax: 3203354 54, Email: bruno.francois@ec-lille.fr
}

\begin{abstract}
This paper presents a new space-vector hysteresis current control (SV-HCC) with neutral point voltage balancing applied on a three-level NPC-VSI. The last supplies a rotor winding of the doubly fed induction generator (DFIG). The proposed control technique controls the power delivered from the wind generator to the electrical network by controlling the rotor currents of the DFIG. It is based firstly on the detection of area and sector in which the error vector tip of the rotor current can be located, secondly, on the neutral voltage sensing. And then on the application of an appropriate voltage vector among the 27 voltage vectors of the three-level NPC-VSI to accomplish two main goals:

1- Controlling the active and reactive powers delivered by the wind generator to the electrical network.

2- Balancing the neutral point voltage of the three-level VSI.
\end{abstract}

\section{Key words}

Space-vector hysteresis current control, active and reactive powers control, three-level NPC-VSI, neutral point voltage balancing, wind power conversion.

\section{Introduction}

Wind energy is becoming one of the most important renewable energy sources in European countries, US, and Asia. Over the past decade, new wind generators of 1-3 MW have been developed and are being installed worldwide [1] and prototypes of higher capacity are under development. As a result, multilevel PWM converters are being increasingly preferred for high power applications such as wind power conversion.

In order to control these converters, many control strategies were proposed. At present, carrier-based modulation (CBM) and space-vector modulation (SVM) [2] have been considered as the most popular modulation strategies for multilevel inverters [3].

However, these control schemes is preferred for voltage control.
The hysteresis controllers are widely used for current control due to their simplicity and robustness [4]. However the phase current interactions, generation of sub-harmonic components in the current and switching losses have been considered as the main drawbacks of the conventional hysteresis controllers [5, 6].

In this paper, a new space-vector hysteresis current control (SV-HCC) is presented for three-level NPC-VSI to accomplish the two following tasks:

1- Controlling the active and reactive powers delivered by the wind generator to the electrical network.

2- Balancing the neutral point voltage of the three-level VSI.

The present paper focuses only on the rotor side converter control of the DFIG using the proposed SV-HCC.

\section{Power system description}

The power system based wind power generation is illustrated in figure 1 . It consists of a wind turbine, a gearbox, a DFIG, and back-to-back three-level converters. The stator winding of the DFIG is directly connected to the grid, whereas its rotor winding is fed by back-to-back threelevel PWM converters. The line side converter is connected to the grid via three chokes to improve the current harmonic distortion. The rotor side converter controls the power flow to the network by controlling the rotor currents of the DFIG.

\section{Dynamic model of the DFIG}

The electric equations in Park reference frame are given as follows:

$$
\left\{\begin{array}{l}
v_{s d}=R_{s} i_{s d}+\frac{d \phi_{s d}}{d t}-\omega_{s} \phi_{s q} \\
v_{s q}=R_{s} i_{s q}+\frac{d \phi_{s q}}{d t}+\omega_{s} \phi_{s d}
\end{array}\right.
$$




$$
\left\{\begin{array}{l}
v_{r d}=R_{r} i_{r d}+\frac{d \phi_{r d}}{d t}-\omega_{r} \phi_{r q} \\
v_{r q}=R_{r} i_{r q}+\frac{d \phi_{r q}}{d t}+\omega_{r} \phi_{r d}
\end{array}\right.
$$

After being developed the electrical equations in the stationary reference frame $[7,8]$, the electrical power equations are given below:

$$
\left\{\begin{array}{l}
P_{s}=-v_{s} \frac{L_{m}}{L_{s}} i_{r q} \\
Q_{s}=\frac{v_{s} \phi_{s}}{L_{s}}-\frac{v_{s} L_{m}}{L_{s}} i_{r d}
\end{array}\right.
$$

The block diagram of the DFIG is depicted in figure2.

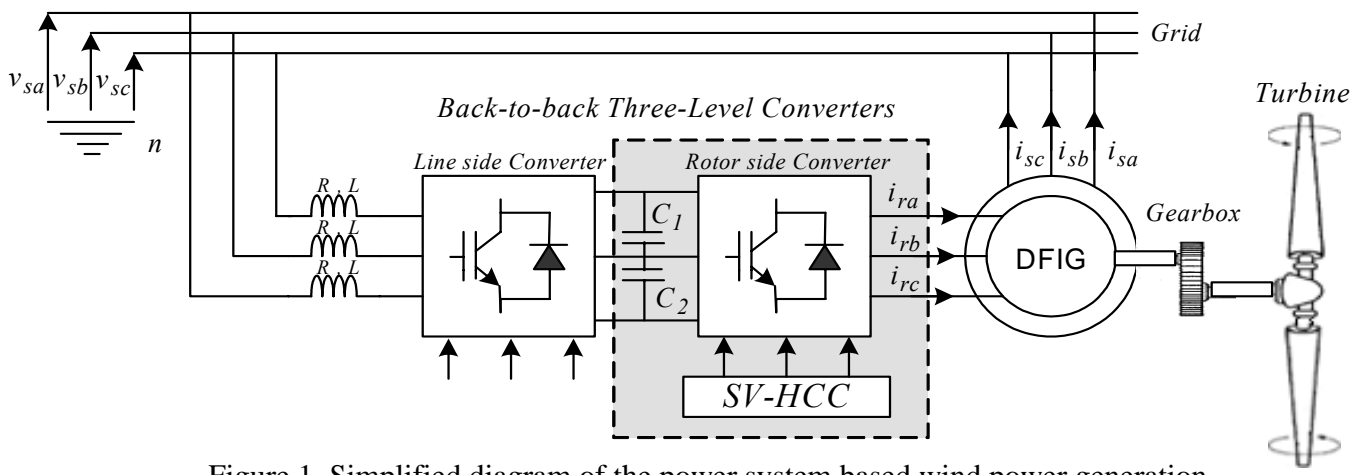

Figure.1. Simplified diagram of the power system based wind power generation

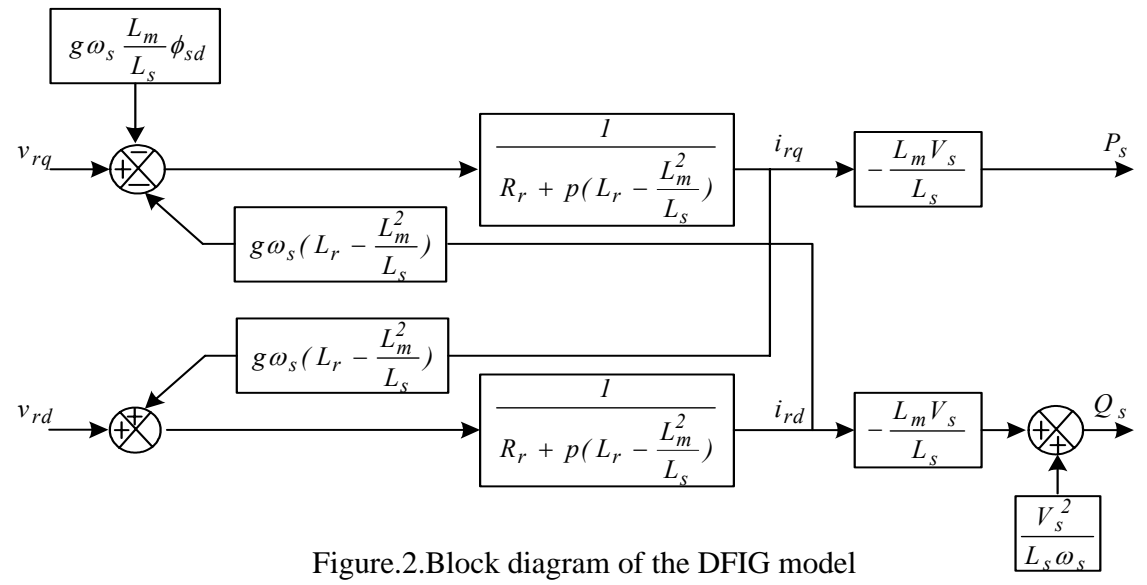

\section{Space-vector hysteresis current control}

\section{A. Overall control system}

The block diagram of the overall control system is shown in figure 3.The active and reactive powers of the DFIG are controlled by means of controlling the direct and quadrature components of its rotor currents. To accomplish this task, two PI controllers and a SV-HCC technique are used.

\section{B. Principle of the space-vector hysteresis current control}

The basic idea of the proposed SV-HCC is to keep the measured rotor currents of the DFIG within their hysteresis boundaries $h_{1}, h_{2}, h_{3}$ all the time.The reference and the measured rotor currents are transformed to $\alpha, \beta$ reference frame. They can be expressed as follows:

$$
\left\{\begin{array}{l}
\bar{i}_{r}^{*}=\bar{i}_{r \alpha}^{*}+j \bar{i}_{r \beta}^{*} \\
\bar{i}_{r}=\bar{i}_{r \alpha}+j \bar{i}_{r \beta}
\end{array}\right.
$$

By the same way, the error vector defined by $\bar{e}=\bar{i}_{r}^{*}-\bar{i}_{r}$ can be given in $\alpha \beta$ reference frame by the following expression:

$$
\bar{e}=\bar{e}_{\alpha}+j \bar{e}_{\beta}
$$

As it is illustrated in figure 4.a, the tip of the reference current vector $\vec{i}_{r}^{*}$ is located in the center of area I whereas the tip of the measured current $\vec{i}_{r}$ can be located in one of the four areas (I, II, III and IV) limited by the hysteresis 
boundaries $h_{1}, h_{2}, h_{3}$ respectively. Table I gives the membership conditions of the error vector tip in the four possible areas. Each one of the three areas II, III and IV is divided into four sectors and area I represents one sector, which is sector $\left(S_{5}\right)$. The sectors are numbered from 1 to 13 . Figure 4.b shows an example of one sector of each area. Table II gives the membership conditions of the error vector tip to the thirteen possible sectors.

TABLE II

THE MEMBER SHIP CONDITIONS OF THE ERROR VECTOR TIP TO THE THIRTEEN SECTORS

\begin{tabular}{|cc|c|c|c|c|}
\hline$e_{\alpha}$ & Area & $\mathrm{e}_{\beta}$ & $\mathrm{A}_{\mathrm{II}}$ & $\mathrm{A}_{\mathrm{III}}$ & $\mathrm{A}_{\mathrm{IV}}$ \\
\hline- & - & $\mathrm{S}_{5}$ & $\mathrm{~S}_{1}$ & $\mathrm{~S}_{6}$ & $\mathrm{~S}_{10}$ \\
\hline+ & - & $\mathrm{S}_{5}$ & $\mathrm{~S}_{2}$ & $\mathrm{~S}_{7}$ & $\mathrm{~S}_{11}$ \\
\hline- & + & $\mathrm{S}_{5}$ & $\mathrm{~S}_{3}$ & $\mathrm{~S}_{8}$ & $\mathrm{~S}_{12}$ \\
\hline+ & + & $\mathrm{S}_{5}$ & $\mathrm{~S}_{4}$ & $\mathrm{~S}_{9}$ & $\mathrm{~S}_{13}$ \\
\hline
\end{tabular}

TABLE I

THE MEMBER SHIP CONDITIONS OF THE ERROR VECTOR TIP TO THE FOURTH AREAS

\begin{tabular}{|c|c|}
\hline Conditions & Areas \\
\hline$\left|e_{\alpha}\right|<h_{1} / 2 \&\left|e_{\beta}\right|<h_{1} / 2$ & I \\
\hline$h_{1} / 2<\left|e_{\alpha}\right|<h_{2} / 2 \& h_{1} / 2<\left|e_{\beta}\right|<h_{2} / 2$ & II \\
\hline$h_{2} / 2<\left|e_{\alpha}\right|<h_{3} / 2 \& h_{2} / 2<\left|e_{\beta}\right|<h_{3} / 2$ & III \\
\hline$\left|e_{\alpha}\right|>h_{3} / 2 \&\left|e_{\beta}\right|>h_{3} / 2$ & IV \\
\hline
\end{tabular}

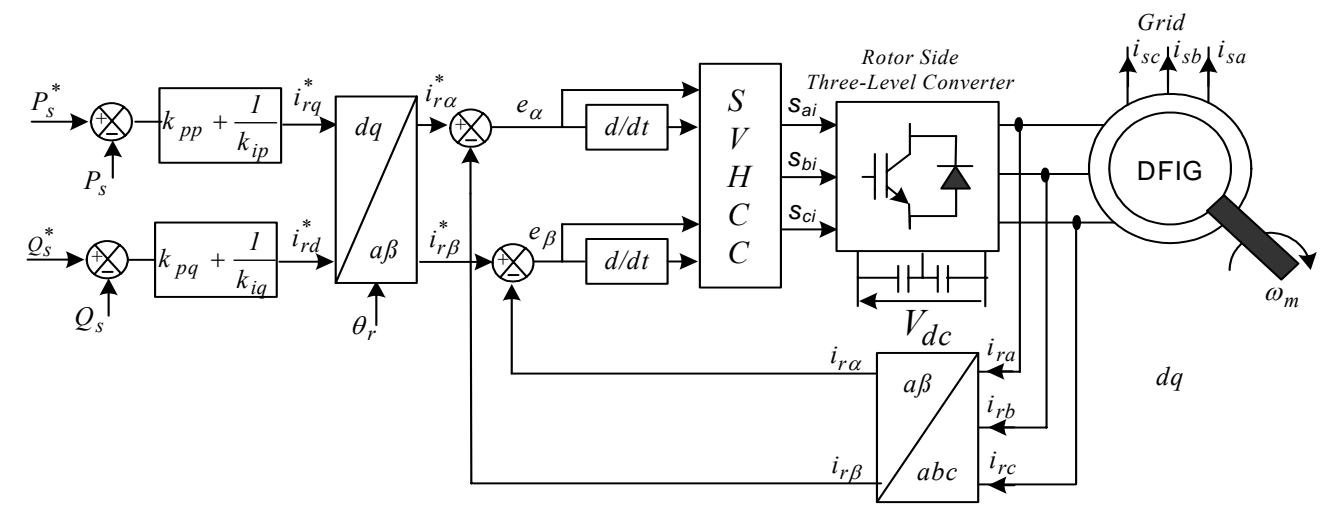

Figure.3.Block diagram of the overall control system

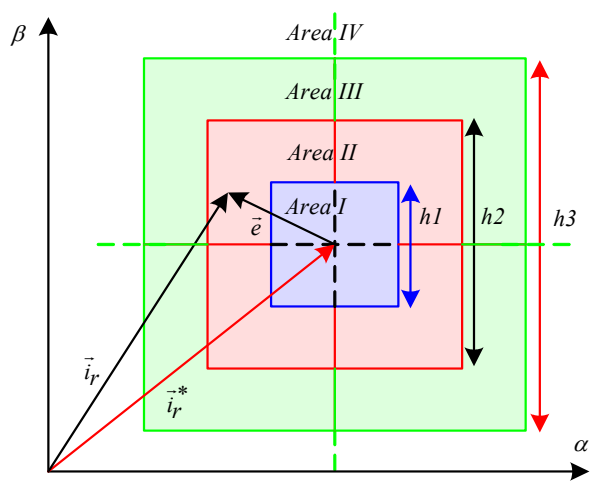

Figure 4.a

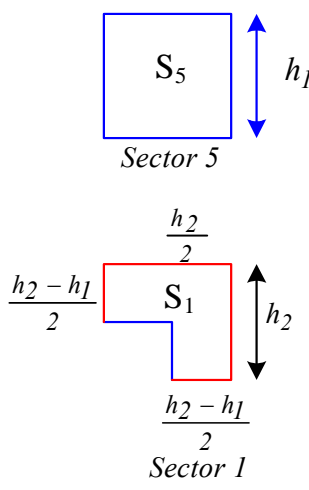

Sector 1

Figure.4. Error vector tip location in the four possible areas and in the thirteen possible sectors

\section{Neutral point voltage balancing}

When zero voltage is applied to any phase, the sum of the currents flowing through the clamping diodes, called $i_{N P}$, produces an unbalanced DC capacitors charging process. By this way, a positive current $i_{N P}$ from the inverter produces a charge in the upper capacitor $\left(C_{1}\right)$, and a negative current produces a discharge in the same capacitor [9] (figure 5). 
A neutral Point unbalance appears when $\Delta v=v_{c 1}-v_{c 2} \neq 0$ or $i_{N P} \neq 0$.

The 27 voltage vectors shown in figure 6 are divided into three categories according to their lengths: large, medium and small. Only the small vectors have two realisations: one positive and one negative switching function. The positive one $\left(\vec{v}_{21}, \vec{v}_{22}, \vec{v}_{23}, \vec{v}_{24}, \vec{v}_{25}, \vec{v}_{26}\right)$ charges the upper capacitor $C_{1}$, whereas the negative one $\left(\vec{v}_{1}, \vec{v}_{2}, \vec{v}_{3}, \vec{v}_{4}, \vec{v}_{5}, \vec{v}_{6}\right)$ discharges it. The neutral point voltage balancing is achieved by sensing the neutral point voltage $\Delta v$, and according to its sign one among the 12 small vectors (positive or negative ones) is applied to charge or discharge the upper capacitor $C_{1}$.

Once the sector is detected, the error derivative is calculated and the neutral point voltage is sensed, an appropriate voltage vector among the 27 voltage vectors shown in figure 6 is applied.

One among the three zero voltage vectors (ZVV) $\left(\vec{v}_{0}, \vec{v}_{7}, \vec{v}_{14}\right)$ is applied when the error vector tip is located in area $\mathrm{I}$.
In the case where the error vector tip is located in area II, one among the small hexagon voltage vectors (figure 6.c) will be applied. By the same way, if the error vector tip is located in area III, one among of the medium hexagon voltage vectors (figure 6.b) will be selected. Otherwise, one of the large hexagon voltage vectors (figure 6.a) will be applied when the error vector tip is located in the area IV (outside areas I, II and III).

Therefore a simple look-up table (table III), which uses the sector information, the error derivative sign and the NP voltage sign, is developed to satisfy the following two conditions at the same time:

1- Controlling the active and reactive powers of the DFIG by controlling its rotor currents.

2- Balancing the neutral point voltage.

Figure 7 shows the control algorithm of the SV-HCC including the neutral point voltage balancing. The hatched part of this algorithm, which is responsible of the neutral point voltage balancing, is involved only when the vector tip of current error $\bar{e}$ is located in area II. Otherwise, there is no need to this part.

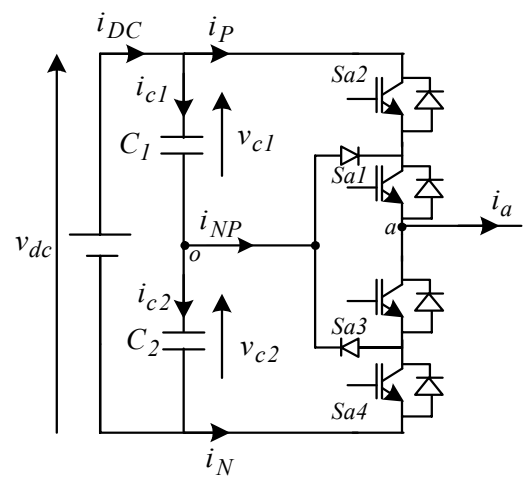

TABLE III

SWITCHING TABLE FOR THE PROPOSED S.V.H.C.C

Figure.5. Neutral point voltage circuit

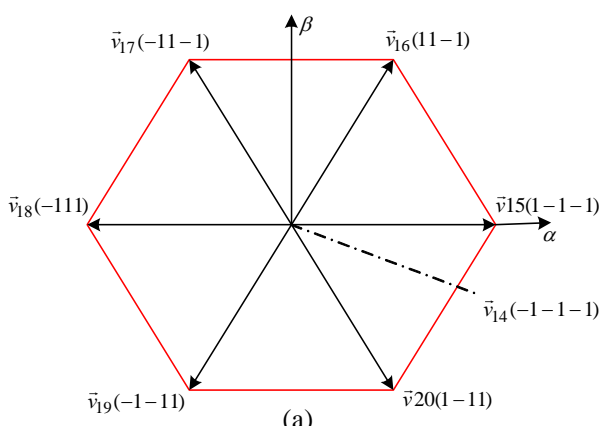

(a)

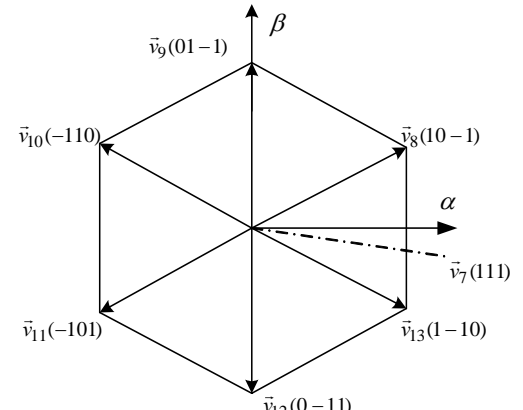

(b) $\vec{v}_{12}(0-11)$

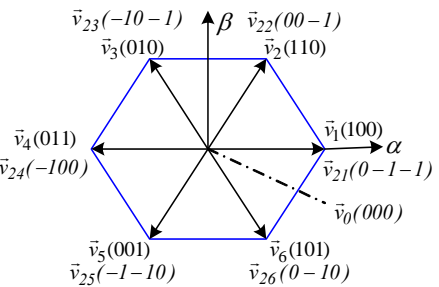

(c)

Figure.6. Three-level voltage inverter vectors in $\alpha \beta$ plane

(a) Large hexagon.

(b) Medium hexagon.

(c) Small hexagon. 


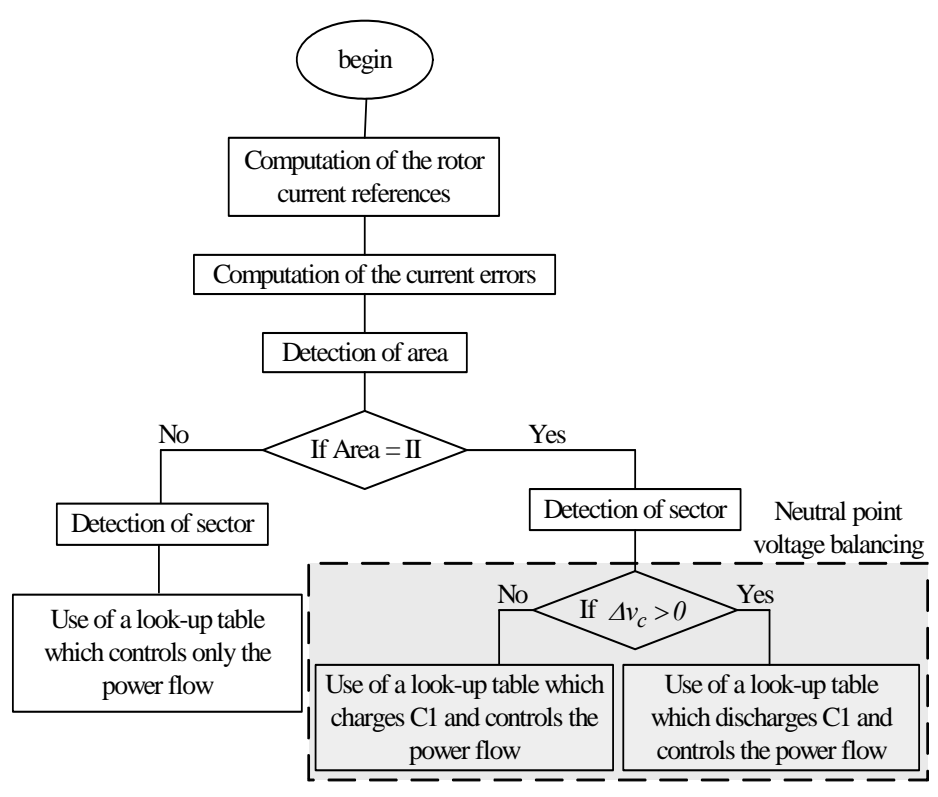

Figure.7. Control algorithm of the SV-HCC including the neutral point voltage balancing

\section{Simulation results}

The proposed SV-HCC technique with neutral point voltage control was tested on three-phase three-level VSI, which controls the active and reactive powers of the DFIG by controlling its rotor currents. The simulation of the overall system shown in figure 1 has been carried out to verify the performances of the proposed control technique. All simulation results are obtained with the following parameters:

-The simulation parameters of the two PI controllers used for active and reactive powers control are: $K_{i p}=2.5, K_{p p}=0.02, K_{i q}=2.5, K_{p q}=0.02$.

-The hysteresis bands of the proposed SV-HCC are fixed at $\left(h_{1}=0.445 \mathrm{~A}, h_{2}=0.47 \mathrm{~A}, h_{3}=0.495 \mathrm{~A}\right)$.

-The speed of the DFIG is fixed at ( $\left.\omega_{m}=1624 r p m n\right)$, and the dc capacitors are fixed at $C_{1}=C_{2}=25 \mathrm{mF}$.

- The DFIG parameters are:

Nominal power $(\mathrm{P}=7.5 \mathrm{KW})$, nominal speed $(\mathrm{N}=1500$ rpmn), pairs of pole number $(\mathrm{p}=2)$, Inertial $\left(\mathrm{J}=0.3125 \mathrm{Kg} \cdot \mathrm{m}^{2}\right)$, viscous coefficient $\left(\mathrm{f}=6.73 .10 \mathrm{e}^{-3} \mathrm{~N} \cdot \mathrm{m} \cdot \mathrm{s}^{-1}\right)$, stator resistance $\left(\mathrm{R}_{\mathrm{s}}=0.455 \Omega\right)$, Stator inductance $\left(\mathrm{L}_{\mathrm{s}}=0.084 \mathrm{H}\right)$, Rotor resistance $\left(\mathrm{R}_{\mathrm{r}}=0.062 \Omega\right)$, rotor inductance $\left(\mathrm{L}_{\mathrm{r}}=0.081 \mathrm{H}\right)$, main inductance $\left(\mathrm{L}_{\mathrm{m}}=0.078\right)$.
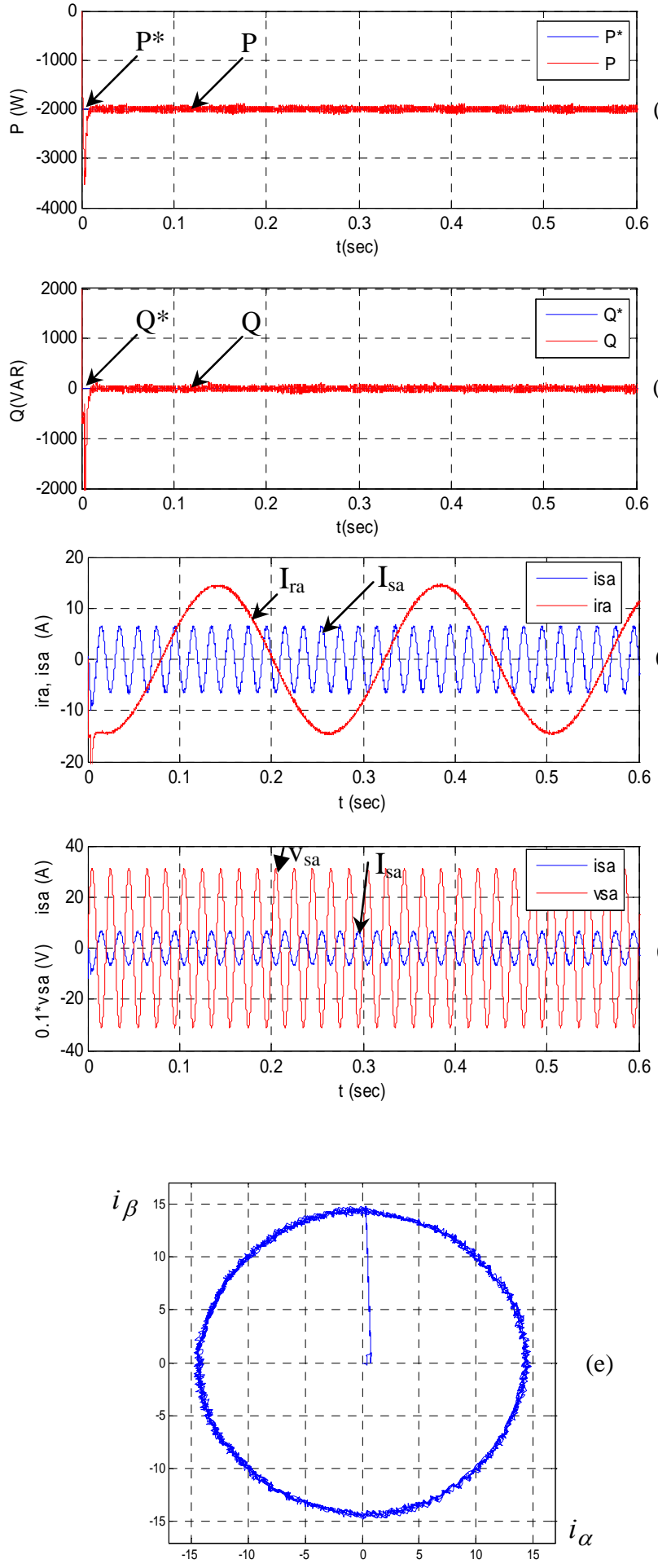

Figure.8. Simulation waveforms of the SV-HCC applied on the rotor side three-level converter

(a) Reference and measured active powers of the DFIG.

(b) Reference and measured reactive powers of the DFIG.

(c) Rotor and stator currents of the DFIG.

(d) Supply voltage and stator current of the DFIG.

(e) The trajectory of the rotor current of the DFIG. 

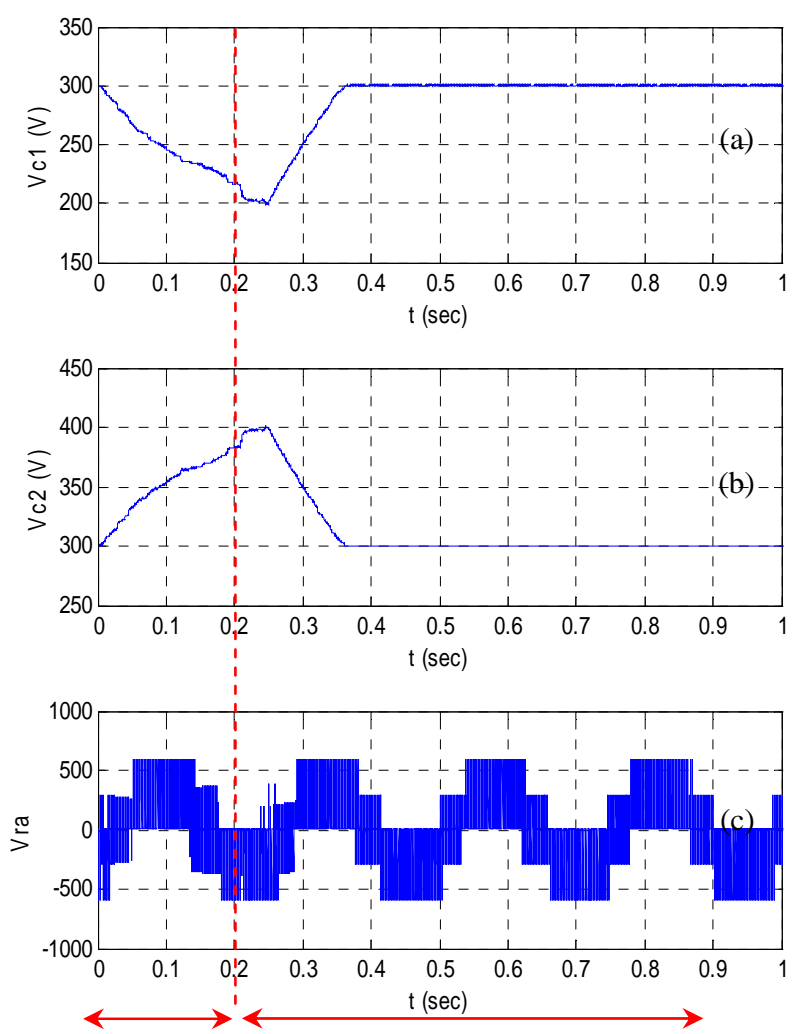

Without NP With NP voltage balancing voltage balancing

Figure.9.Simulation waveforms of the neutral point voltage control

(a) Voltage across the upper capacitor $\mathrm{C}_{1}$.

(b) Voltage across the lower capacitor $\mathrm{C}_{2}$.

(c) Phase to phase output voltage of the three-level VSI

$e \beta$
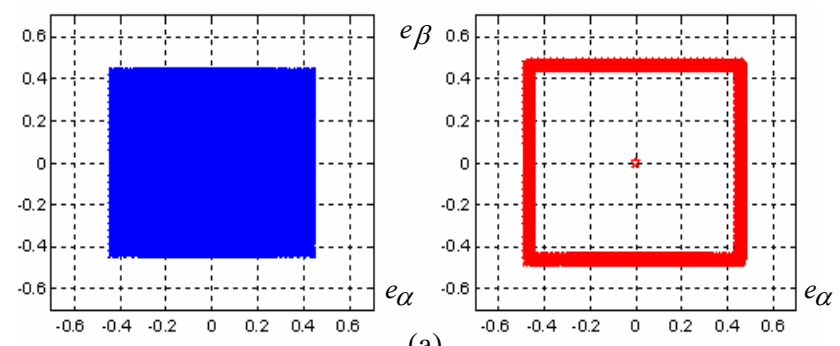

(a)
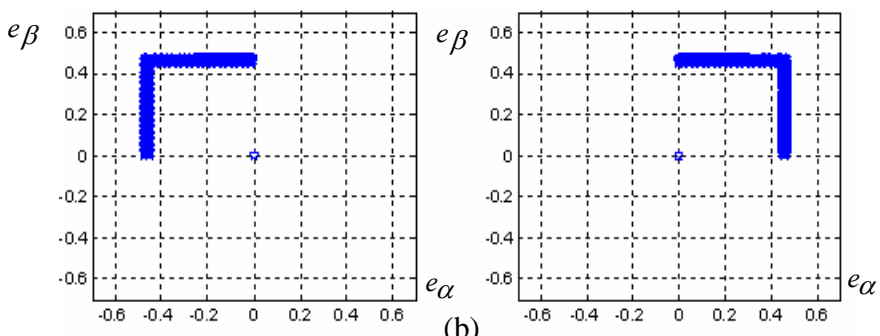

(b)

Figure.10. Current error movement in $\alpha, \beta$ plane

(a) Current error movement in areas I and II

(b) Current error movement in sectors $\mathrm{S}_{1}$ and $\mathrm{S}_{2}$ of area II
Figure 8 illustrates the simulation waveforms of the rotor side three-level converter control shown in figure 1.e. It is clearly seen from figures 8.a and 8.b, that the active and reactive powers of the DFIG follow respectively their references

The stator and rotor currents of the DFIG are shown in figure 8.c. It is obvious that the rotor current frequency is lower than the stator current frequency. It is clear from figure 8.d, that the stator current and the supply voltage are in $\pi$ phase; hence the DFIG injects an active current to the grid. The rotor current trajectory of the DFIG is illustrated in figure 8.e. It is clearly denoted that it is circular in $\alpha, \beta$ plane.

The algorithm of the proposed scheme without the NP voltage balancing part is applied to the three-level VSI before $t=0.25 \mathrm{~s}$. As a result, the upper capacitor $C_{l}$ is discharging and lower capacitor $C_{2}$ is charging. This is clearly noticed in figure 9.a and 9.b. Hence, the NP voltage unbalance affects the three-level VSI output voltages, as it is shown in figure 9.c. Both voltages across the capacitors $v_{c 1}$ and $v_{c 2}$ start to converge towards half of the dc voltage $\left(v_{d c}\right)$ at $t=0.25 \mathrm{~s}$ since the neutral point voltage control is involved.

Figure 10.a shows the current error movement in areas (I and II) and figure 10.billustrates the current error movement in the four sectors of area II.

\section{Conclusion}

A new space- vector based on hysteresis current control has been used in this paper to control the active and reactive powers delivered from the wind generator to the electrical network. Beside this, the control scheme balances the neutral point voltage using redundant inverter switching states. Moreover, it gathers the three current errors into a single space vector quantity. Hence the magnitude of the error vector is limited within a boundary area of a square shape, and also the phase current interactions are avoided in the three phase system. The simulation results of the overall control system show good performances.

\section{References}

[1] P.Gipe, "Soaring to new heights: the world wind energy market”, Renewable energy world, vol5, no.4, pp.33-47, 09/10 2002.

[2] B.P. Grath, , D. G. Holmes, T. Meynard, 'Reduced PWM Harmonic Distortion for Multilevel Inverters Operating Over a Wide Modulation Range', IEEE Transaction on power electronics, July 2006,Vol. 21, No. 4.

[3] P.C.Loh, G.H.Bode, D.G.Holmes, 'Flux modulation for multilevel inverters'. IEEE Trans.Ind. APPL. September/October 2002 vol. 38 No 5, pp 1389-1399.

[4] Kazmierkoswki, M.P., and Malesani, L.: 'Current control techniques for three phase voltage source PWM converters: a survey', IEEE Trans. Ind. Electron., 1998, 45, (5), pp. 691-703 
[5] Nagy. I, 'Novel adaptive tolerance band based PWM for field oriented control of induction machines', IEEE Trans. Ind. Electron., 1994, 41, (4), pp. 406-417.

[6] P.N. Tekwani, R.S. Kanchan and K. Gopakumar, 'Current-error space-vector-based hysteresis PWM controller for three-level voltage source inverter fed drives', IEE Proc.-Electr. Power Appl., September 2005. Vol. 152, No. 5,

[7] S. EL Aimani, B, François, F. Minne, B. Robyns, "Modelling and simulation of doubly fed induction generators for variable speed wind turbines integrated in a distribution network ", 10th European conference on power electronics and applications, Toulouse, France., 2-4 September 2003.

[8] P.Frédéric, "Etude et commande de la génératrice asynchrone pour l'utilisation de l'énergie éolienne”, thèse de doctorat de l'université de Nantes 19 Décembre 2003.

[9] M. Lafoz, I.J. Iglesias, “A Novel Double HysteresisBand Current Control for a Three-Level Voltage Source Inverter", Proceding of the 31st Annual Power Electronics Specialist Conference, Vol. 1, pp 21. 18-23 June 2000. 